\title{
APLICAÇÃO DE CALCÁRIO E CULTURAS DE COBERTURA NA IMPLANTAÇÃO DO SISTEMA PLANTIO DIRETO EM CERRADO $^{(1)}$
}

\author{
Aguinaldo José Freitas Leal ${ }^{(2)}$, Edson Lazarini ${ }^{(3)}$, Leandro Rebuá Rodrigues ${ }^{(4)}$,Cid Tacaoca \\ Muraishi $^{(2)}$, Salatiér Buzetti ${ }^{(5)}$ \& Hipólito Assunção Antonio Mascarenhas ${ }^{(6)}$
}

\begin{abstract}
RESUMO
Este estudo objetivou avaliar a correção do solo no estabelecimento do sistema plantio direto em Latossolo Vermelho localizado em região típica de Cerrado, Selvíria - MS. Os tratamentos consistiram em cinco formas de aplicação de calagem, em dose única ou parcelada, e duas culturas de cobertura. A calagem sem incorporação, independentemente do modo de aplicação, corrigiu a acidez do solo e aumentou os teores de Ca e Mg na camada de 0-0,05 m; nas demais profundidades, não houve alterações significativas desses atributos. A incorporação do calcário na camada de 0-0,2m modificou, uniformemente, os valores de $\mathrm{pH}, \mathrm{Ca}, \mathrm{Mg}$ e soma de bases do solo até à profundidade de $0,2 \mathrm{~m}$. $\mathrm{O}$ sorgo como cultura de cobertura possibilitou maiores teores de Ca e Mg quando a dose de calcário foi subdividida em três aplicações.
\end{abstract}

Termos de indexação: semeadura direta, calagem, sorgo, capim-pé-de-galinha, camadas de solo.

\section{SUMMARY: LIMESTONEAPPLICATIONMETHODSAND COVER CROPS INTHE IMPLEMENTATIONOFTHENO-TILLSYSTEMONACERRADOSOIL}

The objective of this study was to evaluate soil correction in the implantation of the no-till system in an Oxisol of the Cerrado, Selvíria - MS, Brazil $\left(20^{\circ} 22^{\prime} S, 51^{\circ} 22^{\prime} \mathrm{W}\right)$. The

\footnotetext{
(1) Trabalho apresentado no XXXI Congresso Brasileiro de Ciência do Solo, 2007 (Gramado, RS).

(2) Doutorando em Sistema de Produção, Universidade Estadual Paulista - Unesp, Campus de Ilha Solteira. Bolsista Capes. E-mails: aguinaldoleal@yahoo.com.br; ctmuraishi@aluno.feis.unesp.br

(3) Professor do Departamento de Fitotecnia, Tecnologia de Alimentos e Sócio-Economia - Unesp, Campus de Ilha Solteira. CEP15385-000, Av. Brasil, 56, Cx. Postal 31. E-mail: lazarini@agr.feis.unesp.br

(4) Engenheiro-Agrônomo, Ex aluno UNESP - Campus de Ilha Solteira.

(5) Professor do Departamento de Fitossanidade, Engenharia Rural e Solos - Unesp, Campus de Ilha Solteira. E-mail: sbuzetti@agr.feis.unesp.br.

(6) Pesquisador do Instituto Agronômico de Campinas, IAC/APTA. Av. Barão de Itapura, 1481, Vila Itapura, Cx.Postal 28. CEP13001-970, Campinas-SP. E-mail: hipolito@iac.sp.gov.br
} 
treatments consisted of five lime application forms, in only one or split rates and two cover crops. Liming without incorporation, independent of the application form, corrected soil acidity and increased $\mathrm{Ca}$ and $\mathrm{Mg}$ levels in the $0-0.05 \mathrm{~m}$ layer; in the other layers these attributes were not significantly changed. Limestone incorporation in the layer $0-0.2 \mathrm{~m}$, uniformly modified the values of soil $\mathrm{pH}, \mathrm{Ca}, \mathrm{Mg}$ and sum of bases to a depth of $0.2 \mathrm{~m}$. Sorghum as cover crop led to higher $\mathrm{Ca}, \mathrm{Mg}$ concentrations, when liming was split in three applications.

Index terms: no-tillage, surface liming, sorghum, Eleusine coracana, soil layers.

\section{INTRODUÇÃO}

Os anos noventas foram marcados pela preocupação mundial com os impactos ambientais e pela busca de alternativas para minimizá-los. $\mathrm{Na}$ agricultura, os esforços concentraram-se na recuperação do equilíbrio natural do solo, que passa, necessariamente, pelo uso de sistemas de produção sustentáveis, tanto ambiental como economicamente. Neste contexto, se desenvolveu o sistema plantio direto (SPD), caracterizado pelo revolvimento do solo somente na linha de semeadura, favorecendo a cobertura e proteção do solo pelos restos de culturas que antecederam a semeadura.

Para as condições de solos tropicais na maioria pobres, como os encontrados nas regiões de Cerrado, o clima favorece a rápida decomposição dos restos culturais, devendo-se, portanto, atentar para a quantidade e persistência dos resíduos vegetais produzidos pelas espécies antecessoras (Alves et al., 1995). Gramíneas, como sorgo, milheto, milho e, recentemente, o capim-pé-de-galinha (Eleusine coracana), além das braquiárias, podem ser utilizadas no sistema de integração agricultura-pecuária, uma vez que produzem alta quantidade de matéria seca e são capazes de formar uma proteção mais estável na superfície do solo.

O capim-pé-de-galinha é citado na literatura desde a década de 60, Moore (1963). Esse cereal é originário do continente africano (Uganda), onde seus grãos são utilizados na alimentação humana, na forma de farinhas (Oduori, 1994), e na alimentação animal de aves de corte e suínos, além de ser empregado como forrageira na criação de ruminantes (Mushonga, 1994). A introdução dessa espécie no Brasil ocorreu em 1995 na região do Cerrado do Estado de Mato Grosso (Francisco, 2003), como alternativa de entressafra na formação de cobertura do solo para o sistema plantio direto, pois apresenta boa resistência a períodos secos (Mulatu \& Kebede, 1994).

A utilização de sistemas de preparo com o mínimo ou nenhum revolvimento do solo promove melhoria da estrutura, porosidade, retenção e infiltração de água, atividade biológica, conteúdo e teor de $\mathrm{C}$ orgânico e $\mathrm{N}$ total no solo, capacidade de troca de cátions e teores de nutrientes (Bayer \& Mielniczuk, 1997). Entretanto, essas alterações são influenciadas pelas culturas de cobertura e ou produção de grãos utilizados.

Com a adoção do SPD, o calcário é aplicado superficialmente, não sendo incorporado, o que permite questionar quanto à quantidade, freqüência e época de aplicação, nos variados tipos de solo e culturas de cobertura. Espera-se que o calcário aplicado superficialmente modifique atributos químicos, físicos e biológicos do solo que dispensem sua mobilização e a conseqüente descontinuidade do sistema. Em muitos casos, a adição de calcário no sistema plantio direto visa corrigir atributos químicos do solo decorrentes dos cultivos. No entanto, com a rápida expansão do SPD no Cerrado em áreas recémincorporadas à produção agrícola, anteriormente sob pastagem ou vegetação, normalmente com altos índices de acidez, torna necessária a correção do solo ainda na fase de instalação.

Neste contexto, este trabalho foi realizado com o objetivo de avaliar, no sistema de plantio direto em Latossolo localizado em região típica de Cerrado, o efeito de diferentes modos e épocas de aplicação do calcário e de culturas de cobertura, na entressafra, em atributos químicos do solo.

\section{MATERIAL E MÉTODOS}

O experimento foi realizado na Fazenda de Ensino e Pesquisa da Universidade Estadual Paulista - UNESP, Campus de Ilha Solteira, localizada no município de Selvíria-MS, (51ํ2' W e 20²2' S e altitude de $335 \mathrm{~m}$ ). O local apresenta clima tropical úmido com estação chuvosa no verão e seca no inverno, com temperatura e precipitação pluvial média anual de $24,5^{\circ} \mathrm{C}$ e 1.232 $\mathrm{mm}$, respectivamente. $\mathrm{O}$ solo foi classificado como Latossolo Vermelho distrófico típico argiloso A moderado hipodistrófico álico caulinítico férrico, compactado, muito profundo, moderadamente ácido (LVd), em média com $660 \mathrm{~g} \mathrm{~kg}^{-1}$ de argila, $120 \mathrm{~g} \mathrm{~kg}^{-1}$ de silte e $220 \mathrm{~g} \mathrm{~kg}^{-1}$ de areia, na camada de $0-0,2 \mathrm{~m}$. Anterior à instalação do experimento, a área foi cultivada com culturas anuais, em sistema convencional de preparo do solo (aração e ou grade pesada + grade niveladora). Nesta área, realizou-se uma amostragem de solo na camada de 0-0,2 $m$ antes da instalação do experimento, conforme os resultados obtidos na análise química (Quadro 1). 
Quadro 1: Análise química ${ }^{(1)}$ do solo anterior à instalação do experimento

\begin{tabular}{|c|c|c|c|c|c|c|c|c|c|c|c|}
\hline Prof. & P-resina & M.O. & $\underset{\mathrm{CaCl}_{2}}{\mathbf{p H}}$ & $\mathbf{K}$ & $\mathrm{Ca}^{2+}$ & $\mathbf{M g}^{2+}$ & $\mathrm{H}+\mathrm{Al}$ & $\mathrm{Al}^{3+}$ & SB & $\begin{array}{c}\text { CTC } \\
\text { pH 7,0 }\end{array}$ & V \\
\hline $\mathrm{m}$ & $\mathrm{mg} \mathrm{dm}^{-3}$ & $\mathrm{~g} \mathrm{dm}^{-3}$ & 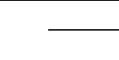 & 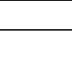 & 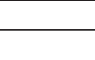 & - & $\mathrm{Amol}_{\mathrm{c}} \mathrm{dm}$ & & & 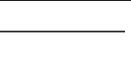 & $\%$ \\
\hline $0-0,2$ & 37 & 26 & 4,7 & 2,1 & 19 & 11 & 34 & 2 & 31,7 & 65,7 & 48 \\
\hline
\end{tabular}

(1) Método de Raij \& Quaggio (1983).

O método utilizado para o cálculo da necessidade de calagem foi para aumentar a saturação por bases para $70 \%$ (Raij et al., 1996). O resultado obtido na análise do solo indicou a dose de calcário de 1,59 t ha $^{-1}$; utilizou-se, na correção, calcário dolomítico com PRNT de $91 \%$ com $39 \%$ de $\mathrm{CaO}$ e $13 \%$ de $\mathrm{MgO}$. Os tratamentos consistiram em cinco modos de aplicação da dose de calcário recomendada: a) aplicação da dose total em outubro de 2001, incorporada a $0-0,2 \mathrm{~m}$; b) dose total em superfície em outubro de 2001; c) aplicação de $1 / 2$ da dose recomendada em outubro de 2001 e metade em agosto de 2002 , em superfície; d) aplicação de 1/3 da dose em março de 2001, 1/3 em outubro de 2001 e 1/3 em agosto 2002, todas em superfície e e) tratamento-testemunha (sem calcário). Utilizaram-se duas culturas de entressafra semeadas na primavera, objetivando a cobertura do solo [capimpé-de-galinha (Eleusine coracana L. Gaertn)] e sorgo (Sorghum bicolor L. Moench). As culturas de cobertura foram instaladas sem adubação no sulco de semeadura. A cultura produtora de grãos utilizada foi a soja (Glycine max L. Merrill), variedade MGBR46 (Conquista), com espaçamento de $0,45 \mathrm{~m}$ entrelinhas. Na semeadura da soja, utilizou-se a semeadora-adubadora apropriada para o sistema plantio direto, com sistema de deposição de adubo tipo haste (facão). Como adubação, foram aplicados $250 \mathrm{~kg} \mathrm{ha}^{-1}$ da fórmula 08-28-16 + 0,02 \% de Zn, nos dois anos agrícolas.

O calcário foi distribuído manualmente nas parcelas, de forma uniforme e a lanço. $O$ tratamento com calcário incorporado abrangeu duas aplicações: metade da dose foi aplicada antes da aração e metade antes da gradagem.

O delineamento experimental utilizado foi o inteiramente casualizado com três repetições. Os tratamentos foram dispostos em um esquema fatorial $5 \times 2 \times 4$ (época e modos de aplicação de calcário x culturas de cobertura x camadas de amostragem, consideradas como terceiro fator). A parcela experimental tinha dimensões de 12 x $15 \mathrm{~m}$, desprezando-se $3,0 \mathrm{~m}$ em cada extremidade e $3,5 \mathrm{~m}$ em cada lateral, perfazendo um total de $48 \mathrm{~m}^{2}$ de área útil, onde foram colhidas duas subamostras por parcela em quatro profundidades, em abril de 2003, pela abertura de minitrincheiras transversais às linhas de plantio, com 0,45m de largura (espaçamento de semeadura da soja) e 0,40m de profundidade. Após a limpeza de uma das faces, retirou-se em quatro intervalos de profundidade $(0-0,05 ; 0,05-0,10 ; 0,10$ 0,20 e 0,20 a $0,40 \mathrm{~m}$ ) uma porção de aproximadamente $0,03 \mathrm{~m}$ de espessura, com auxílio de uma pá de corte, de acordo com recomendações de Cantarutti et al. (1999). Das subamostras homogeneizadas, coletou-se a amostra composta que foi analisada em laboratório, determinando-se o $\mathrm{pH}$, os teores de $\mathrm{P}, \mathrm{K} \mathrm{Ca}^{2+}, \mathrm{Mg}^{2+} \mathrm{e}$ a CTC a pH 7,0 e a saturação por bases de acordo com método descrito por Raij \& Quaggio (1983).

Os dados obtidos foram analisados estatisticamente pelo teste $\mathrm{F}$ e as médias comparadas pelo teste de Tukey a $5 \%$, com o auxílio do programa estatístico Sanest (Zonta \& Machado, 1984).

\section{RESULTADOS E DISCUSSÃO}

Os teores de $\mathrm{P}$ não foram influenciados significativamente pelos modos de aplicação de calcário no sistema plantio direto (SPD). No entanto, os teores de $\mathrm{P}$ foram influenciados pela cultura de cobertura utilizada e pela profundidade de amostragem do solo, havendo uma interação entre estes fatores (Figura 1). A utilização do sorgo como cultura antecessora proporcionou maior teor de P na camada de 0,05-0,1 m, diferenciando das parcelas onde se utilizou o capim-péde-galinha, que apresentou teores superiores desse elemento na camada de 0,1-0,2 m. Em relação às profundidades avaliadas, verificou-se acúmulo do P nas camadas até $0,2 \mathrm{~m}$ de profundidade, em razão provavelmente do local de deposição do adubo no momento da semeadura, considerando a baixa mobilidade do $\mathrm{P}$ no solo e o não-revolvimento deste neste sistema de semeadura. As diferenças obtidas entre as culturas de cobertura podem ser atribuídas à profundidade de maior concentração do sistema radicular de cada espécie e à quantidade absorvida, considerando as diferenças de produção de matéria seca, conforme relatado por Leal (2003).

Os modos de aplicação de calcário em superfície, dose total ou parcelada, promoveram a neutralização da acidez da camada superficial (0-0,05 m), enquanto a incorporação propiciou uma correção do solo uniforme até os $0,20 \mathrm{~m}$, sem, no entanto, diferenciar estatisticamente dos modos de aplicação em superfície (Figura 2), concordando com dados obtidos por Amaral \& Anghinoni (2001). Provavelmente isso ocorreu por que, quando incorporado, o efeito do calcário dilui-se 
em uma camada mais espessa, como relatado por Moreira et al. (2001). A aplicação de calcário, independente-mente do modo, promoveu teores de $\mathrm{Ca}^{2+}$, $\mathrm{Mg}^{2+}$ superiores aos encontrados nas parcelas que não receberam corretivo, até à camada de 0,1-0,2 m, mas apenas os tratamentos que receberam calcário em superfície diferenciaram-se da testemunha na camada superficial, 0-0,05 m. Mello et al. (2003), ao avaliarem os efeitos de doses de calcário na fase de implantação em SPD, decorridos 12 meses da aplicação em um Latossolo distroférrico em Botucatu-SP, observaram efeito da aplicação em superfície sobre os valores de $\mathrm{C}^{2+} \mathrm{e} \mathrm{Mg}^{2+}$ na camada de 0-0,05 m e na subseqüente, de 0,05-0,10 m, demonstrando que a correção do solo em profundidade no SPD demanda certo tempo após a aplicação, e este período é variável de acordo com as características edafoclimáticas locais. De forma semelhante, Oliveira \& Pavan (1996) obtiveram

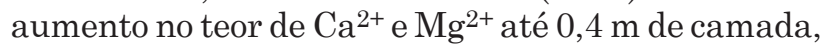
após 32 meses da aplicação na superfície de um Latossolo argiloso, bem como Caires et al. (2000) verificaram em um Latossolo Vermelho-Escuro de Ponta Grossa-PR aumentos significativos nos teores de $\mathrm{Ca}^{2+}$ na camada de 0-0,2 m, após 28 e 30 meses da aplicação.

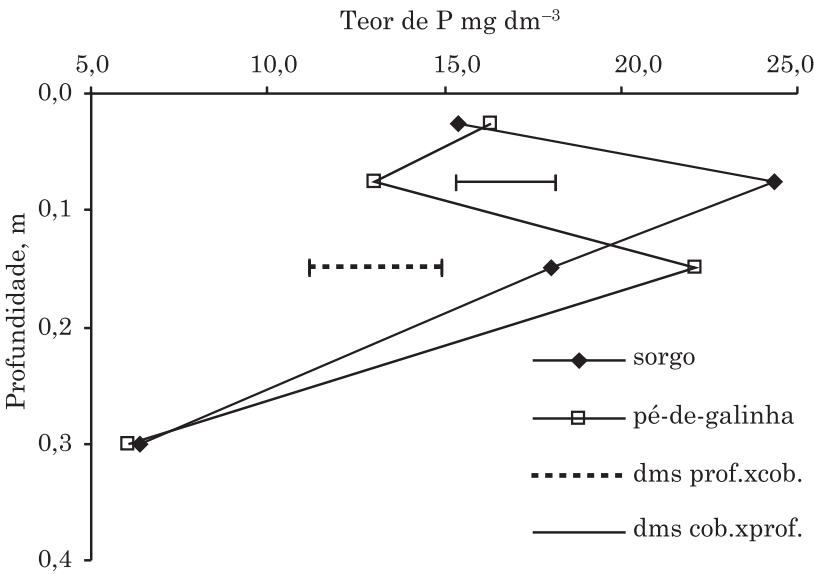

Figura 1. Teores médios de fósforo no solo em função da camada de solo amostrada e das culturas de cobertura em sistema plantio direto $(\mathrm{dms}=$ diferença mínima significativa, Tukey a $5 \%$.

O emprego de calcário dolomítico incorporado na camada de 0-0,2 $\mathrm{m}$ foi insuficiente para manter os teores médios de $\mathrm{Mg}^{2+}$ no solo, nas camadas de 0,05 0,1 e 0,1-0,2 m, nos valores observados anteriormente (Quadro 1 e Figura 2). Observou-se que o tratamento sem calcário apresentou teores médios de $\mathrm{Mg}^{2+}$ bem abaixo dos observados antes da instalação do experimento, nas camadas de 0,05-0,1 e 0,1-0,2 m, sugerindo perda gradativa deste nutriente por lixiviação, pois, segundo Vitti \& Trevisan (2000), são exportados apenas $2 \mathrm{~kg}$ de $\mathrm{Mg}$ por tonelada de grãos de soja produzidos.

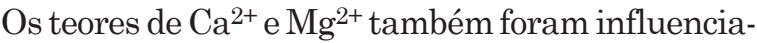
dos pela interação entre culturas de cobertura e modos de aplicação do calcário (Figura 3). A cultura do sorgo promoveu teores de $\mathrm{Ca}^{2+}$ e $\mathrm{Mg}^{2+}$ superiores aos encontrados no solo sob palha de capim-pé-de-galinha, quando o calcário foi aplicado parcelado em três vezes. Esta cultura de cobertura também promoveu maiores teores de $\mathrm{Ca}^{2+}$ quando o corretivo foi incorporado.

Na figura 2, também estão apresentados os valores médios de $\mathrm{pH}$, teores de $\mathrm{K}$, soma de bases e CTC a pH 7,0 nos diferentes modos de aplicação de calcário e nas diferentes camadas de profundidade amostradas. Observou-se pouca ação do calcário aplicado em superfície nas camadas subseqüentes, mesmo após transcorridos 18 meses da aplicação no tratamento total em superfície e $1 / 2+1 / 2$, ou 24 meses da primeira parcela do tratamento com três aplicações $(1 / 3+1 / 3+$ 1/3). Resultados semelhantes foram relatados por Santos et al. (2003), ao avaliarem os efeitos de doses e formas de aplicação da calagem em SPD, em um Argissolo Vermelho em Santa Maria-RS, e por Moreira et al. (2001), que também não observaram aumentos nos teores de $\mathrm{Ca}^{2+}$ e valores de $\mathrm{pH}$ abaixo da camada de 0 $0,05 \mathrm{~m}$, após oito meses da aplicação da dose recomendada de calcário em superfície, independentemente do tempo de cultivo sob sistema plantio direto avaliado. Os valores de $\mathrm{pH}$ do solo obtidos nos tratamentos com aplicação de calcário em superfície foram superiores aos da testemunha, apenas na camada de 0-0,05m, destacando-se também nesta camada os maiores valores obtidos com os tratamentos aplicação total em superfície ou parcelado em duas vezes, em relação a tratamento com incorporação; no entanto, esse apresentou efeito mais uniforme em relação às profundidades avaliadas. Apesar de a aplicação em superfície não se diferenciar estatisticamente da testemunha, nas camadas de 0,05-0,10 e 0,10-0,20m, aparentemente observou-se efeito do corretivo nessas profundidades 18 meses após o seu emprego.

Houve acúmulo de $\mathrm{K}$ nas camadas mais superficiais (Figura 2), fato também verificado por Caires et al. (1998). Este fato, provavelmente, está relacionado com a extração de $\mathrm{K}$ de camadas inferiores pelas raízes das culturas e sua posterior deposição na superfície do solo, por meio da decomposição dos restos culturais, caracterizando, assim, um processo de ciclagem deste nutriente. A aplicação de calcário em superfície proporcionou os menores teores de $\mathrm{K}$ na camada superficial $(0-0,05 \mathrm{~m})$ quando comparado com a testemunha sem a aplicação e a incorporação do calcário, sugerindo a existência de uma correlação negativa entre os teores de $\mathrm{K}$ trocável e teores de $\mathrm{Ca}^{2+}$ e $\mathrm{Mg}^{2+}$ trocável, provavelmente pela competição pelos mesmos sítios de troca. Os valores de CTC a pH 7,0 apresentaram as maiores médias na camada superficial de 0-0,05 m com a calagem em superfície, acompanhando o comportamento dos teores de $\mathrm{Ca}^{2+} \mathrm{e}$ $\mathrm{Mg}^{2+}$. A cultura do sorgo proporcionou teores de $\mathrm{Ca}^{2+}$, $\mathrm{Mg}^{2+}$ e soma de bases superiores aos obtidos quando se utilizou o capim-pé-de-galinha antecedendo a soja. 

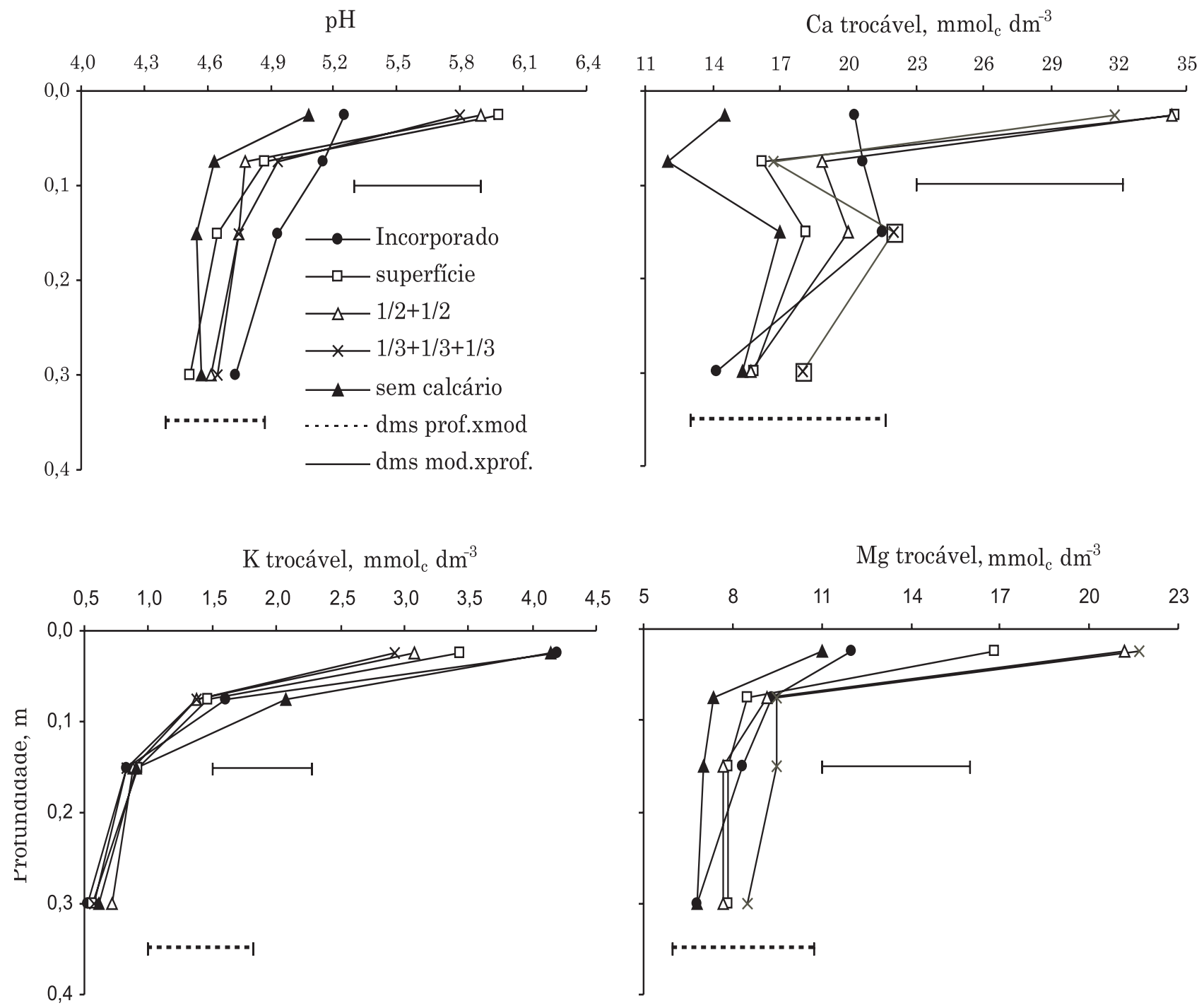

Soma de bases, $\mathrm{mmol}_{\mathrm{c}} \mathrm{dm}^{-3}$

CTC, $\mathrm{mmol}_{\mathrm{c}} \mathrm{dm}^{-3}$
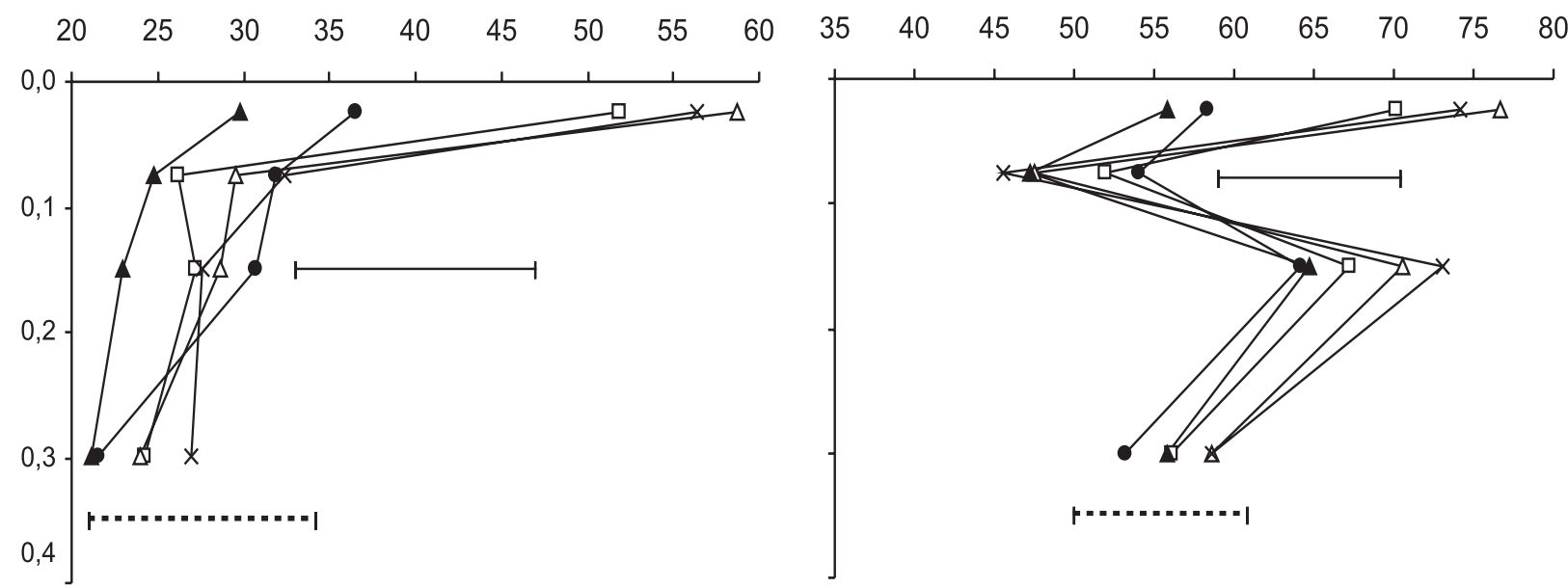

Figura 2. Médias de $\mathrm{pH}$, teores de bases $\left(\mathrm{Ca}^{2+}, \mathrm{Mg}^{2+}\right.$ e $\left.\mathrm{K}^{2+}\right)$, soma de bases e CTC a $\mathrm{pH} 7,0$ considerando a profundidade de amostragem e modos de aplicação de calcário. (dms = diferença mínima significativa, Tukey a $5 \%$ ). 

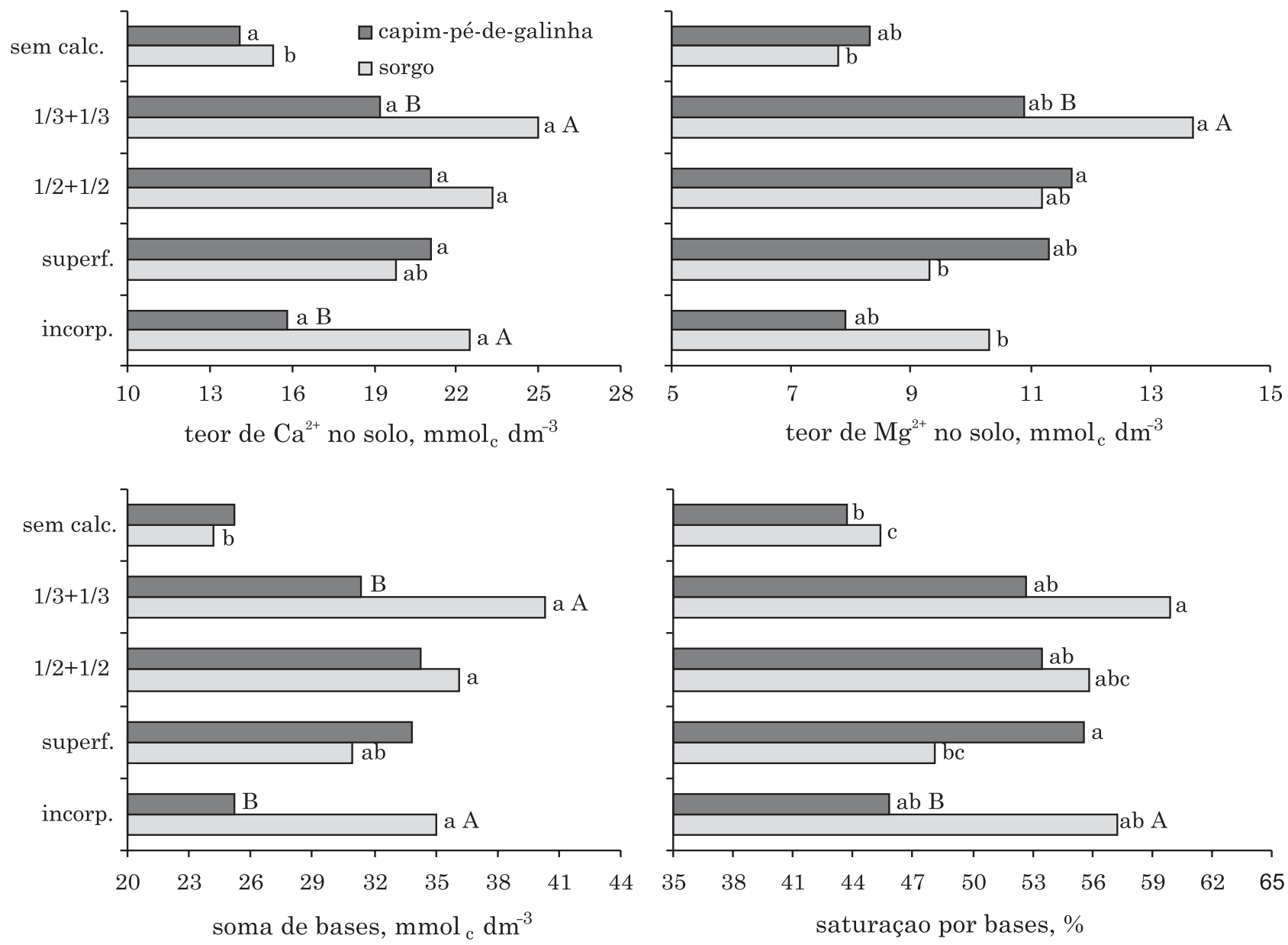

Figura 3. Teores médios de $\mathrm{Ca}^{2+}, \mathrm{Mg}^{2+}$, soma de bases e saturação por bases, considerando interação entre modos de aplicação de calcário na implantação do sistema plantio direto e culturas de cobertura do solo (letras minúsculas distintas, diferença entre os modos de aplicação de calcário; maiúsculas distintas diferença entre as culturas de cobertura Tukey a $5 \%$ ).

A saturação por bases do solo foi influenciada pela interação entre culturas de cobertura e modos de aplicação (Figura 3). O maior valor de saturação por bases foi obtido na camada de 0-0,05 m (67,6\%), um pouco abaixo do valor pretendido (70\%). A camada de 0-0,05 $\mathrm{m}$ apresentou as maiores médias de saturação por bases do solo, devido ao aumento dos teores de $\mathrm{K}$, $\mathrm{Ca}^{2+} \mathrm{e} \mathrm{Mg}^{2+}$ nessa camada; resultado semelhante ao obtido por Moreira et al. (2001). A camada de 0,05-0,1 m apresentou saturação média de 55,1\%. A média da saturação por bases das duas camadas superficiais (0-0,05 m e 0,05-0,1 m) é aproximadamente 61,4 $\%$, valor muito próximo dos $62 \%$, apontado por Nolla \& Anghinoni (2006) como critério para definição da necessidade de calagem para o cultivo de soja em SPD sob Latossolo Vermelho aluminoférrico no Planalto Riograndense (RS).

Portanto, os resultados demonstram o efeito limitado da calagem sem incorporação aos $0,05 \mathrm{~m}$ superficiais do solo, independentemente do modo de aplicação do calcário utilizado em superfície. Portanto, nas condições edafoclimáticas de Cerrado, a correção efetiva do solo em camadas inferiores a $0,05 \mathrm{~m}$, pela aplicação superficial de calcário em SPD, demandará intervalo de tempo superior a 18 meses.

\section{CONCLUSÕES}

1. Após 18 meses da aplicação de calcário em superfície, na implantação do SPD, seu efeito foi observado apenas na camada superficial (0-0,05 m), independentemente do modo ou cultura de cobertura utilizada.

2. A aplicação de calcário incorporado antes da instalação do SPD proporcionou alterações uniformes no $\mathrm{pH}, \mathrm{Ca}^{2+}, \mathrm{Mg}^{2+}$ e na soma de bases do solo na camada de 0-0,2 m.

3. O sorgo como cultura de cobertura proporcionou maiores teores de bases trocáveis no solo quando a calagem foi dividida em três aplicações. 


\section{LITERATURA CITADA}

ALVES, A.G.C.; COGO, N.P. \& LEVIEN, R. Relações da erosão do solo com a persistência da cobertura vegetal morta. R. Bras. Ci. Solo, 19:127-132, 1995.

AMARAL, A.S. \& ANGHINONI, I. Alterações de parâmetros químicos do solo pela reaplicação superficial de calcário no sistema plantio direto. Pesq. Agropec. Bras., 36:695$702,2001$.

BAYER, C. \& MIELNICZUK, J. Conteúdo de nitrogênio total em um solo submetido a diferentes métodos de preparo e sistemas de cultura. R. Bras. Ci. Solo, 21:235239, 1997.

CAIRES, E.F.; CHUEIRI, W.A.; MADRUGA, E.F. \& FIGUEIREDO, A. Alterações de características químicas do solo e resposta da soja ao calcário e gesso aplicados na superfície em sistema de cultivo sem preparo do solo. R. Bras. Ci. Solo, 22:27-34, 1998.

CAIRES, E.F.; BANZATO, D.A. \& FONSECA, A.F. Calagem na superfície em sistema plantio direto. R. Bras. Ci. Solo, 24:161-169, 2000.

CANTARUTTI, R.B.; ALVAREZ V., V.H. \& RIBEIRO, A.C. Amostragem de solo. In: RIBEIRO, A.C.; GUIMARÃES, P.T.G. \& ALVAREZ V., V.H., eds. Recomendações para o uso de corretivos e fertilizantes em Minas Gerais - $5^{a}$ Aproximação. Viçosa, MG, Comissão de Fertilidade de Solo do Estado de Minas Gerais, 1999. p.13-20.

FRANCISCO, E.A.B. Antecipação da adubação da soja na cultura de Eleusine coracana (L.) Gaertn., em sistema de plantio direto. Piracicaba, Escola Superior de Agricultura "Luiz de Queiroz", 2003. 55p. (Dissertação de Mestrado)

LEAL, A.J.F. Efeitos na cultura da soja de modos e épocas de aplicação de calcário e culturas de cobertura do solo na implantação do sistema plantio direto. Ilha Solteira, Universidade Estadual Paulista, 2003. 67p. (Trabalho de Graduação)

MELLO, J.C.A.; VILLAS BÔAS, R.L.V.; LIMA, E.V. \& CRUSCIOL, C.A.C. Alterações nos atributos químicos de um Latossolo distroférrico decorrentes da granulometria e doses de calcário em sistema plantio direto e convencional. R. Bras. Ci. Solo, 27:553-561, 2003.
MOORE, A.W. Nitrogen fixation in Latosolic soil under grass. Plant Soil, 19:127-138, 1963.

MOREIRA, S.G.; KIEHL, J.C.; PROCHNOW, L.I. \& PAULETTI, V. Calagem em sistema de semeadura direta e efeitos sobre a acidez do solo, disponibilidade de nutrientes e produtividade de milho e soja. R. Bras. Ci. Solo, 25:71-81, 2001.

MULATU, T. \& KEBEDE, Y. Finger millet importance and improvement in Ethiopia. In: RILEY, K.W.; GUPTA, S.C.; SEETHARAM, A. \& MUSHONGA, J.N. Advances in small millets. New York, International Science, 1994. p.51-59.

MUSHONGA, J.N. Advances in small millets. New York, International Science, 1994. p.67-73.

NOLLA, A. \& ANGHINONI, I. Critérios de calagem para a soja no sistema plantio direto consolidado. R. Bras. Ci. Solo, 30:475-483, 2006.

ODUORI, C.O. Small millets production and research in Kenya. In: RILEY, K.W.; GUPTA, S.C.; SEETHARAM, A. \& MUSHONGA, J.N Advances in small millets. New YTork: International Science, 1994. cap. 7, p.67-73.

OLIVEIRA, E.L. \& PAVAN, M.A. Control of soil acidity in notillage system for soybean productions. Soil Till. Res., 38:47-57, 1996.

RAIJ, B.van; CANTARELLA, H. \& QUAGGIO, J.A., eds. Recomendações de adubação e calagem para o Estado de São Paulo. Campinas, Instituto Agronômico de Campinas, 1996. 285p. (Boletim Técnico, 100)

RAIJ, B.van \& QUAGGIO, J.A. Métodos de análise química do solo para fins de fertilidade. Campinas, Instituto Agronômico de Campinas, 1983. 31p. (Boletim Técnico, 81)

SANTOS, M.V.C.; ELTZ, F.L.F.; HICKMANN, C. \& STEFANELO, C. Avaliação de doses e formas de calagem em sistema plantio direto após sete anos. In: CONGRESSO BRASILEIRO DE CIÊNCIA DO SOLO, 29., Ribeirão Preto, 2003. Resumo Expandido. Ribeirão Preto, Sociedade Brasileira de Ciência do Solo, 2003. CD-ROM.

VITTI, G.C. \& TREVISAN, W. Manejo de macro e micronutrientes para alta produtividade da soja. In: CÂMARA, G.M.S., ed. Soja: tecnologia da produção II. Piracicaba, Escola Superior de Agricultura Luiz de Queiroz, 2000. p.383-422.

ZONTA, E.P. \& MACHADO, A.A. Sanest - Sistema de análise estatística para microcomputadores. Pelotas, Universidade Federal de Pelotas, 1984. 138p. 
